\title{
Rotational conjunctival flap surgery reduces recurrence of pterygium
}

\author{
Johan Eksteen, Andries A Stulting, Mariette Nel
}

To the Editor: The ocular condition called pterygium (also known as web eye) is a triangular patch of hypertrophied subconjunctival tissue extending from the medial canthus of the eye to the border of the cornea or beyond, with the apex pointing towards the pupil. ${ }^{1,2}$ It is one of the most common conditions of the conjunctiva, and surgery to remove pterygia is practised widely. ${ }^{3}$

Ultraviolet radiation is a major environmental risk factor for the development of pterygium, ${ }^{2,4}$ especially UVB $(290-320 \mathrm{~nm})$ exposure. ${ }^{3}$ Other risk factors include genetic predisposition, ${ }^{5-7}$ dry eyes, ${ }^{2,3}$ low humidity, and chronic micro-trauma caused by cigarette smoke, dust and sand particles. ${ }^{3}$ The highest prevalence of pterygium was found in countries within $37^{\circ}$ latitude north and south of the Equator. Prevalence also increases with age., ${ }^{2,8}$

Pterygium is medically managed at first, mainly by symptom control and minimising the factors that promote its progression. Application of ocular decongestants, such as topical non-steroidal antiinflammatory agents (NSAIDs) or topical steroids, for brief periods to reduce inflammation and swelling usually achieves symptom control. The frequent use of artificial tears is recommended, as keratoconjunctivitis sicca is often associated with pterygium. Widebrimmed hats and sunglasses minimise exposure to UV radiation. ${ }^{9}$

Surgery involves excision of the pterygium, primarily aiming at its complete removal and to prevent recurrence. Indications for pterygium removal include involvement of the visual axis, progressive growth approaching the visual axis, and pterygium extending $\geq 3 \mathrm{~mm}$ onto the cornea. ${ }^{10}$ Pterygium removal could also be performed in the event of contact lens intolerance, chronic irritation, patients' cosmetic concerns, or unusual-looking pterygia mimicking dysplasia. When surgery for minor indications is considered, the risk of complications and recurrence should be weighed against the symptoms causing the patient distress. ${ }^{2,11}$

We aimed to compare the recurrence rate following primary pterygium surgery using two different techniques, i.e. simple conjunctival closure (SCC) and rotational conjunctival flap (RCF). Postoperative discomfort and complications were also investigated in these patients.

\section{Patients and methods}

A prospective randomised comparative study was conducted: 41 patients (60 eyes) underwent surgery between 9 January and 6 February 2007 at the National District Hospital in Bloemfontein for

Department of Ophthalmology, Faculty of Health Sciences, University of the Free State, Bloemfontein

Johan Eksteen, MB ChB, MMed (Ophth), FCOphth (SA)

Andries A Stulting, MB ChB, MMed (Ophth), FCS (Ophth) (SA), FRCOphth

Department of Biostatistics, Faculty of Health Sciences, University of the Free State, Bloemfontein

Mariette Nel, MMedS the removal of primary pterygia. Age and gender were recorded. Patients' eyes were randomly divided into two groups, by means of sealed envelopes. In addition to pterygium excision, group 1 included 31 eyes on which SCC was performed, and group 2 comprised 29 eyes on which RCF was performed. Patients were followed up on days 1 , 14, 90 (3 months), 180 (6 months) and 365 (1 year). A 1-year cut-off was chosen for follow-up because recurrence of pterygia is most likely to occur within 6 - 12 months postoperatively. ${ }^{10}$ All affected eyes were photographed pre-operatively and on the follow-up days. Surgery and follow-up were performed by one ophthalmologist. Approval to conduct the investigation was granted by the Ethics Committee of the Faculty of Health Sciences, University of the Free State (UFS). Written, informed consent was obtained from all participants. Data analysis was performed by the Department of Biostatistics, UFS.

\section{Results}

The median age of patients in group 1 (SCC) was 53.6 years (range 29 - 66.7 years). In group 2 (RCF), patients' ages ranged between 25.4 and 87 years (median 49 years). In group 1, 18.2\% of patients were male; in group 2, 34\% were male. No statistical difference was found between the two groups regarding age and gender.

The pterygia recurrence rates of the two groups at 1-year followup were (i) SCC group: $66.7 \%$ (20 eyes) and (ii) RCF group: $20.7 \%$ (6 eyes). The difference was statistically significant (95\% confidence interval (CI) $20.9-63.8 \%$ ). With regard to severity, pterygia were divided into severe ( $\geq 4 \mathrm{~mm}$ from the limbus) and moderate $(<4 \mathrm{~mm}$ from the limbus). Table I shows the recurrence rate of pterygia at 3-, 6- and 12-month follow-up, and the association between size of pterygia and recurrence.

Group 1 (eyes on which SCC was performed) spent between 5 and 25 minutes (median 12 minutes) in theatre. Group 2 (eyes on which RCF was performed) were in surgery between 12 and 26 minutes (median 20 minutes). The difference in median times was statistically significant (95\% CI - 10 - -5).

No significant difference was found between the two groups regarding the development of adverse postoperative sequelae. Three patients in each group experienced complications after pterygium excision. Complications in group 1 included graft dehiscence (1 patient) and prolonged retained suture material (2 patients). In group 2, one patient had a retained suture, another developed dense opacification of the cornea underlying the pterygium area, and a third patient developed a chronically irritated left eye.

No patient reported extreme discomfort or pain following surgery. In group $1,38.7 \%$ of patients experienced no discomfort, while the remainder reported moderate discomfort. In group 2, 39.3\% of patients experienced no discomfort, and the remainder reported mild discomfort.

\section{Discussion}

The SCC method had a significantly higher recurrence rate of pterygia (66.7\%) than the RCF technique (20.7\%). In another study, that did not state the criteria for recurrence, a recurrence rate of $5.6 \%$ was associated with the RCF technique. ${ }^{12}$ In our study, $20.7 \%$ of eyes in the RCF group had recurrent pterygia, which was much higher than expected. Our results could possibly have been influenced 
Table I. Recurrence of pterygia ( $i)$ at different stages of postoperative follow-up; and (ii) in relation to the pre-operative size, at 12-month follow-up

\begin{tabular}{|c|c|c|c|c|c|}
\hline & \multicolumn{2}{|c|}{$\begin{array}{l}\text { Group } 1\left(N=30 \text { eyes }^{\star}\right) \\
\text { Simple closure }\end{array}$} & \multicolumn{2}{|c|}{$\begin{array}{c}\text { Group } 2(N=29 \text { eyes }) \\
\text { Rotational flap }\end{array}$} & \multirow[b]{2}{*}{$95 \%$ CI } \\
\hline & $N$ & $\%$ & $N$ & $\%$ & \\
\hline \multicolumn{6}{|c|}{$\begin{array}{l}\text { (i) Recurrence of pterygia at } \\
\text { different stages of follow-up }\end{array}$} \\
\hline 3 months & 14 & 45.2 & 3 & 10.3 & $(12.2-53.2 \%)^{\dagger}$ \\
\hline 6 months & 19 & 63.3 & 4 & 14.3 & $(24.3-66.2 \%)^{\dagger}$ \\
\hline 12 months & 20 & 66.7 & 6 & 20.7 & $(20.9-63.8 \%)^{\dagger}$ \\
\hline \multicolumn{6}{|c|}{$\begin{array}{l}\text { (ii) Recurrence of pterygia } \\
\text { in relation to their pre-operative } \\
\text { size, at } 12 \text {-month follow-up }\end{array}$} \\
\hline \multicolumn{6}{|l|}{ Pterygium $<4 \mathrm{~mm}$} \\
\hline Pre-operative & 26 & & 25 & & \\
\hline 12-month follow-up & 17 & $65.4(17 / 26)$ & 5 & $20.0(5 / 25)$ & $(18.3-64.2 \%)^{\dagger}$ \\
\hline \multicolumn{6}{|l|}{ Pterygium $\geq 4 \mathrm{~mm}$} \\
\hline Pre-operative & 4 & & 3 & & \\
\hline 12-month follow-up & 3 & $75.0(3 / 4)$ & 1 & $25.0(1 / 4)$ & $(-13.5-78.9 \%)$ \\
\hline
\end{tabular}

by the learning curve concerning surgical skill in performing the procedure. Surgery time decreased as the surgeon became more familiar and experienced with the RCF technique. Although more difficult and initially taking longer to perform than SCC, RCF was more successful.

Size could not be regarded as a significant predictor of recurrence, as recurrence was similar for smaller $(<4 \mathrm{~mm})$ and more severe $(\geq 4$ $\mathrm{mm})$ pterygia. No serious complications or extreme discomfort were associated with either of these two conjunctival closure techniques.

We thank Daleen Struwig, medical writer, Faculty of Health Sciences, University of the Free State, for technical and editorial preparation of the manuscript.

\section{References}

1. Stedman's Medical Dictionary. 28th ed. Philadelphia: Lippincott Williams \& Wilkins, 2006.

2. Kanski JJ. Clinical Ophthalmology. A Systematic Approach. 6th ed. Edinburgh: Butterworth Heinemann, 2007.
3. Saw S, Tan D. Pterygium: prevalence, demography and risk factors. Ophthalmic Epidemiol 1999;6: 219-228.

4. Coroneo MT. Pterygium as an early indicator of ultraviolet insolation: a hypothesis. Br J Ophthalmol 1993;77:734-739

5. Hecht F, Shoptaugh MG. Winglets of the eye. Dominant transmission of early adult pterygium of the conjunctiva. J Med Genetics 1990;27:392-394.

6. McKeown CM, Harris R. An autosomal dominant multiple pterygium syndrome. J Med Genetics 1988;25:96-103.

7. Jang JD. An investigation of aetiology and heredity of pterygium. Report of 11 cases in a family. Acta Ophthalmol 1987;65:413-416.

8. Cameron ME. Pterygium Throughout the World. Springfield: Charles C Thomas, 1965 .

9. Gans LA, surgical treatment of pterygium. In: Belin MW, ed. Focal Points: Clinical Modules for Ophthalmologists. San Francisco: American Academy of Ophthalmology, 1996;14:1-14.

10. Hirst LW. The treatment of pterygium. Surv Ophthalmol 2003;48:145-180.

11. Tan DT, Chee SP, Dear KB, Lim AS. Effect of pterygium morphology on pterygium recurrence in a controlled trial comparing conjunctival autografting with bare sclera excision. Arch Ophthalmol 1997; 115:1235-1240.

12. Kim S, Yang Y, Kim J. Primary pterygium surgery using the inferior conjunctival transposition flap. Ophthalmic Surg Lasers 1998;29:608-611. 